\title{
Prediction of retail beef yield, trim fat and proportion of high-valued cuts in Nellore cattle using ultrasound live measurements
}

\section{Saulo da Luz e Silva ${ }^{1}$, Jaime Urdapilleta Tarouco ${ }^{2}$, José Bento Sterman Ferraz ${ }^{1}$, Rodrigo da Costa Gomes ${ }^{1}$, Paulo Roberto Leme ${ }^{1}$, Elly Ana Navajas ${ }^{3,4}$}

\author{
${ }_{1}^{1}$ Faculdade de Zootecnia e Engenharia de Alimentos, Universidade de São Paulo, Pirassununga, SP, Brazil. \\ ${ }^{2}$ Faculdade de Agronomia, Universidade Federal do Rio Grande do Sul, Porto Alegre, RS, Brazil. \\ ${ }^{3}$ Sustainable Livestock Systems Group, Scottish Agricultural College, West Mains Road, Edinburgh, EH9 3JG, Scotland, UK. \\ ${ }^{4}$ Instituto Nacional de Investigación Agropecuaria, Montevideo, Uruguay.
}

\begin{abstract}
The objective of this study was to develop equations to predict retail product and fat trim (weights and percentages) for Nellore (Bos indicus) cattle. Live ultrasound measurements of the longissimus muscle area, backfat thickness at the 12th rib and rump fat depth and shrunk body weight were obtained from 218 Nellore steers to predict weights and percentages of carcass retail product, pistola retail product and fat trimmings. After slaughter, carcasses were deboned and weighed and percentages of retail cuts were obtained directly. Measurements taken directly in the carcasses explained $97 \%$ and $36 \%$ of variation in carcass retail product weight and percentage, and $94 \%$ and $36 \%$ of variation in pistola retail weight and percentage, respectively. Live measurements explained $93 \%$ of carcass retail product weight and $39 \%$ of carcass retail product percentage. Lower accuracies were observed for pistola retail product weight $\left(R^{2}=0.87\right)$ and percentage $\left(R^{2}=0.33\right)$. Accuracies for fat trimmings weight and percentage were $79 \%$ and $55 \%$, respectively. Ultrasound rump fat thickness showed greater correlations with retail product and fat trimmings (weights and percentages) when compared with ultrasound backfat thickness. The weight and percentage of retail products and of trimmable fat can be estimated in Nellore steers from live animal measurements, with similar accuracy to equations developed based on carcass measurements obtained at slaughter.
\end{abstract}

Key Words: beef, Bos indicus, fat, retail product, ultrasound

\section{Introduction}

Beef carcass composition is of high economic importance for the beef industry. Weights and proportions of meat in the carcass, which are quantified by traits such as retail product, are indicators of the quality of carcasses based on the amount of product to be commercialized. Furthermore, the assessment of carcass fat content, both in terms of absolute weight and as a proportion of the carcass are significant for the economic efficiency of production, human health and to help reduce waste as a result of trimmed fat (Lambe et al., 2010).

Important variations in the composition of meat animals and their carcasses result from different factors along with the beef chain from breeding to transport and marketing practices (Hedrick, 1983). Wolcott et al. (2001) observed significant differences between live animal measurements and retail product when modeled for different market category, finishing regime and breed classifications, suggesting that specific equations considering these factors could improve retail product prediction accuracy.
The effect of the breed may determine different relative importance of the beef carcass measurements in their contribution to carcass composition due to possible differences in carcass composition and tissue distributions. Influences of breed on saleable meat yield (Ball \& Johnson, 1989) and on fat partitioning within the subcutaneous depot between rib and rump sites in cattle have been reported (Hopkins et al., 1993; Walmsley et al., 2010).

Most of the studies on the use of in vivo ultrasound or carcass measurements to predict retail product were developed using Continental and British cattle breeds and their crosses (Herring et al., 1994; Realini et al., 2001; Wolcott et al., 2001), with cattle fed to significantly ticker subcutaneous fat endpoint than normally observed for Zebu cattle under Brazilian conditions. Consequently, this information may not be directly extrapolated to Bos indicus breeds which are usually slaughtered at low levels of subcutaneous fat depth.

A better understanding of the impact of the different ultrasound traits on the prediction of carcass composition in Bos indicus may contribute to a more efficient use of the 
information generated by the genetic evaluation to improve carcass quality.

Therefore, the objective of this study was to develop equations to predict retail product and fat trim (weights and percentages) for Nellore (Bos indicus) cattle using live ultrasound measurements.

\section{Material and Methods}

Data from 218 Nellore steers raised at the experimental beef cattle farm of Faculdade de Zootecnia e Engenharia de Alimentos of Universidade de São Paulo (FZEA/USP), Brazil, located at $21^{\circ} 59^{\prime} \mathrm{S}, 47^{\circ} 27^{\prime} \mathrm{W}$ were recorded. Animals were raised under grazing conditions until finishing. Before slaughter, the animals were feedlot-finished (70-90 days; average daily gain of $1.35 \pm 0.25 \mathrm{~kg}$ /day) with concentrate-based diets (60-80\%) and corn silage as the roughage source. Age at slaughter ranged between 24 and 30 months.

In vivo measurements were recorded within 3-5 days before slaughter and after $16 \mathrm{~h}$ of fasting. Realtime ultrasound images were collected and measured by an experienced technician using one of two ultrasound technologies: i) Pie Medical Scanner 200 Vet (Pie Medical Inc., Maastricht, The Netherlands) equipped with a $3.5 \mathrm{MHz}$, $180 \mathrm{~mm}$ linear array (year 1; three scans and harvest groups); ii) an Aloka 500V (Aloka CO. LTD, Tokio, Japan) with a $3.5 \mathrm{MHz}, 172 \mathrm{~mm}$ linear array (year 2; five scans and harvest groups). Vegetable oil was used as a couplant to obtain adequate acoustic contact between the transducer and animal skin. Ultrasound images were saved in a personal computer using a video frame capture board (Pinnacle Studio 500-USB; Pinnacle Systems Inc., Montain View, CA, USA). Images were interpreted using software Lince (M\&S Consultoria Agropecuária Ltda, Pirassununga, SP, Brazil), which was properly calibrated before interpreting the images to take into account possible differences between the two equipments.

The live animal traits evaluated were: 1) shrunk body weight at scanning (SBW); 2) longissimus muscle area between the 12th and 13th ribs (ULMA); 3) Fat thickness at three-quarters of the distance from the lateral end of longissimus muscle, between the 12th and 13th ribs (UFAT); 4) Rump fat thickness at the junction of the Biceps femoris and Gluteus medius muscles, between the ischium and illium, and parallel to the vertebral column (URFAT).

Animals were slaughtered at the abattoir of FZEA/USP in accordance to the Humanitarian Slaughter Guidelines as required by Brazilian laws. Kidney, pelvic and inguinal (udder and cod) fats were removed in the slaughter line before weighting of the carcasses. Then, carcasses were longitudinally divided in two halves, washed, weighed (hot carcass weight; $\mathrm{HCW}$ ) and chilled for 24 hours at $0-2{ }^{\circ} \mathrm{C}$. After chilling, the right side of each carcass was divided between the 12th and 13th ribs, where carcass longissimus muscle area (CLMA) and fat thickness (CFAT) were measured. The left side of each carcass was first cut into wholesale pistola hindquarter, forequarter and combined plate, flank and short ribs. The hump weight was recorded and added to forequarter weight.

Subsequently, wholesale cuts were individually weighed and divided into retail cuts, bones and trimmings. Retail cuts were defined as all cuts trimmed of excess fat to a thickness of approximately $5 \mathrm{~mm}$. Trimmings were calculated by difference (wholesale cut weight minus the weight of retail cuts and bones), and total retail product (RP) weight and total fat trimmings were obtained as the sum of the weights of those tissues in the wholesale cuts. Percentages of total RP and fat trimmings were calculated by dividing their respective weights by the left carcass weight $\times 100$. Because the most valuable cuts of carcass are located in the pistola hindquarter, the ability of live and carcass measurements to predict the weight and percentage of pistola RP was also investigated. The percentage of pistola RP was calculated by dividing its weight by the carcass weight $\times 100$.

Statistical analyses were conducted using software SAS (Statistical Analysis System, version 9.2). Pearson product-moment correlations between live and carcass measurements and carcass composition traits (weights and percentages) were calculated.

Regression equations using live (SBW, ULMA, UFAT and URFAT) or carcass traits (HCW, CLMA and CFAT) to predict the weights and percentages of carcass and pistola RP and trimmings were fitted using linear stepwise regression analysis (REG procedure of SAS). All first-order interactions between independent variables were tested.

The goodness-of-fit of the equations was assessed using coefficient of determination $\left(\mathrm{R}^{2}\right)$, standard error of prediction (SEP) and the coefficient of Mallow (Cp; Mallow, 1973).

\section{Results and Discussion}

The present study evaluated 218 steers, with mean SBW of $507 \mathrm{~kg}$ and mean CFAT of $6.4 \mathrm{~mm}$ (Table 1). The mean values, standard deviations, maximum and minimum values of the traits can be considered as representative 
of averages and ranges of Brazilian finished beef cattle (Millen et al., 2009).

Correlations between ultrasound and carcass traits were high (Table 2). The coefficients found between in vivo and post-mortem traits were 0.90 for the longissimus area and 0.85 for backfat thickness. Rump fat thickness was only measured in vivo, so the correlation was not calculated.

The live measurement that showed that the strongest correlation with carcass and pistola RP weight was SBW ( $r=0.94$ and $\mathrm{r}=0.90$, respectively), whilst ULMA had a more moderate association with them $(r=0.69$ and $r=0.71$, respectively). Fat measurements (UFAT and URFAT) also presented positive but smaller correlation coefficients with those traits $(\mathrm{r}=0.42$ to $\mathrm{r}=0.48)$.

When RP was expressed as percentage, SBW was negatively associated with carcass $(\mathrm{r}=-0.28)$ and pistola $(\mathrm{r}=-0.43)$ RP weight. Muscle measurements (ULMA and CLMA) were weakly or not associated with both traits $(\mathrm{r}=0.04$ to 0.16$)$ whilst both in vivo and carcass fat measurements had stronger correlations with RP percentages ( $\mathrm{r}=-0.36$ to -0.44$)$.

Among the in vivo measurements of fat, URFAT showed similar correlations with carcass and pistola RP percentages ( $\mathrm{r}=-0.49$ and $\mathrm{r}=-0.42$, respectively) and slightly higher than UFAT ( $\mathrm{r}=-0.44$ and $\mathrm{r}=-0.36$, respectively). These results differed from those reported by Greiner et al. (2003), in which UFAT had higher correlation with carcass

Table 1 - Descriptive statistics for live animal and carcass traits

\begin{tabular}{lccccc}
\hline Variable & $\mathrm{N}$ & Mean & $\mathrm{SD}$ & Minimum & Maximum \\
\hline \multicolumn{5}{c}{ Live measurements } \\
SBW (kg) & 218 & 507.7 & 61.6 & 385.0 & 683.0 \\
ULMA (cm $\left.{ }^{2}\right)$ & 218 & 70.8 & 8.9 & 53.3 & 98.9 \\
UFAT $(\mathrm{mm})$ & 218 & 6.4 & 2.5 & 1.9 & 14.8 \\
URFAT (mm) & 218 & 9.2 & 3.1 & 2.8 & 21.5 \\
& Carcass measurements & & \\
HCW (kg) & 218 & 293.4 & 41.7 & 226.9 & 402.9 \\
KPIF (\%) & 218 & 4.7 & 0.9 & 2.6 & 6.8 \\
CLMA (cm $\left.{ }^{2}\right)$ & 218 & 70.4 & 8.6 & 54.0 & 101.0 \\
CFAT (mm) & 218 & 6.8 & 2.9 & 2.0 & 15.0 \\
KGRP (kg) & 218 & 201.6 & 27.8 & 157.6 & 275.9 \\
PRP (\%) & 218 & 69.8 & 1.6 & 65.9 & 73.1 \\
KGRPPHQ (kg) & 218 & 95.4 & 12.6 & 74.7 & 129.5 \\
PRPPHQ (\%) & 218 & 33.1 & 1.4 & 28.7 & 36.5 \\
KGTFAT (kg) & 218 & 36.9 & 10.1 & 20.6 & 68.8 \\
PTFAT (\%) & 218 & 6.3 & 1.0 & 4.4 & 9.3 \\
\hline
\end{tabular}

SBW - shrunk body weight on scan date; ULMA - ultrasound of the longissimus muscle area between the 12th and 13th ribs; UFAT - ultrasound of subcutaneous fat thickness between the 12th and 13th ribs; URFAT - ultrasound of subcutaneous fat measured over the biceps femoris muscle; HCW - hot carcass weight; KPIF - kidney, pelvic and inguinal fat weight expressed as percentage of total carcass weight; CLMA - carcass longissimus muscle area between the 12th and 13th ribs; CFAT carcass subcutaneous fat thickness between the 12th and 13th ribs; KGRP - weight of carcass retail product; PRP - retail product weight expressed as percentage of carcass weight; KGRPPHQ - weight of retail product in the pistola hindquarter; PRPPHQ retail product in the pistola hindquarter expressed as percentage of carcass weight; KGTFAT - weight of carcass trimmed fat $(5 \mathrm{~mm})$; PTFAT - trimmed fat weight expressed as a percentage of carcass weight; SD - standard deviation.
RP percentage $(\mathrm{r}=-0.74)$ than URFAT $(\mathrm{r}=-0.66)$. Likewise, Tait et al. (2005) found a stronger correlation of UFAT with percentage of retail cuts in the four primals $(\mathrm{r}=-0.58)$ when compared with URFAT $(\mathrm{r}=-0.43)$. The higher correlations of URFAT with all traits suggest that this trait could be more informative than UFAT to predict retail products in Zebu cattle.

There are few studies in the literature on the association between live measurements and retail product in the pistola hindquarter. Tarouco et al. (2007), who evaluated the ability of live animal measurements to estimate retail cuts in the pistola hindquarter in Braford steers, found a low correlation between SBW and percentage of RP in pistola hindquarter $(\mathrm{r}=-0.06)$. Similarly, Tait et al. (2005) reported a low correlation $(\mathrm{r}=-0.12)$ between body weight and percentage of RP in primal cuts of Angus bulls and steers. The weaker correlation observed by Tarouco et al. (2007) could be related to the narrower range in SBW observed in that study $(134 \mathrm{~kg})$, because the animals evaluated belonged to the same contemporary group and were slaughtered at lower and similar degree of fat, if compared with the present investigation.

Hot carcass weight was highly correlated with both total RP weight $(\mathrm{r}=0.98)$ and pistola hindquarter RP weight $(\mathrm{r}=0.96)$, but when retail cuts were expressed as percentage of the carcass or primal weight, the correlation coefficients were smaller and negative $(r=-0.27$ and $\mathrm{r}=-0.37$, respectively).

Table 2 - Pearson product-moment correlations of live animal and carcass traits with carcass retail product, pistola hindquarter retail product and fat trimmings weights and percentages

\begin{tabular}{lcccccl}
\hline Trait & KGRP & PRP & KGRPPHQ & PRPPHQ & KGTFAT & PTFAT \\
\hline \multicolumn{7}{c}{ Live measurements } \\
SBW & $0.94^{* * * *}$ & $-0.28^{* *}$ & $0.90^{* * *}$ & $-0.43^{* * *}$ & $0.83^{* * *}$ & $0.55^{* * *}$ \\
ULMA & $0.69^{* * *}$ & $0.16^{* *}$ & $0.71^{* * *}$ & 0.04 & $0.43^{* * *}$ & $0.14^{*}$ \\
UFAT & $0.44^{* * *}$ & $-0.44^{* * *}$ & $0.42^{* * *}$ & $-0.36^{* * *}$ & $0.62^{* * *}$ & $0.62^{* * *}$ \\
URFAT & $0.48^{* * *}$ & $-0.49^{* * *}$ & $0.45^{* * *}$ & $-0.42^{* * *}$ & $0.66^{* * *}$ & $0.64^{* * *}$
\end{tabular}

Carcass measurements

$\begin{array}{lllllll}\text { HCW } & 0.98^{* * *} & -0.27^{* * *} & 0.96^{* * *} & -0.37^{* * * *} & 0.87^{* * *} & 0.59^{* * *} \\ \text { KPIF } & 0.29^{* * * *} & -0.41^{* * *} & 0.22^{* *} & -0.45^{* * *} & 0.46^{* * *} & 0.49^{* * *} \\ \text { CLMA } & 0.67^{* * *} & 0.17^{*} & 0.69^{* * *} & 0.04 & 0.41^{* * *} & 0.13^{\#} \\ \text { CFAT } & 0.43^{* * *} & -0.43^{* * *} & 0.39^{* * *} & -0.42^{* * *} & 0.62^{* * *} & 0.62^{* * *}\end{array}$

SBW - shrunk body weight on scan date; ULMA - ultrasound of the longissimus muscle area between the 12th and 13th ribs; UFAT - ultrasound of subcutaneous fat thickness between the 12th and 13th ribs; URFAT - ultrasound of subcutaneous fat measured over the biceps femoris muscle; HCW - hot carcass weight; KPIF - kidney, pelvic and inguinal fat weight expressed as percentage of total carcass weight; CLMA - carcass longissimus muscle area between the 12th and 13th ribs; CFAT carcass subcutaneous fat thickness between the 12th and 13th ribs; KGRP - weight of carcass retail product; PRP - retail product weight expressed as percentage of carcass weight; KGRPPHQ - weight of retail product in the pistola hindquarter; PRPPHQ retail product in the pistola hindquarter expressed as percentage of carcass weight; KGTFAT - Weight of carcass trimmed fat $(5 \mathrm{~mm})$; PTFAT - trimmed fat weight expressed as a percentage of carcass weight.

*** $\mathrm{P}<0.0001 ; * * \mathrm{P}<0.001 ; * \mathrm{P}<0.05$. 
Similar trend was observed between SBW and RP weights and percentages because of the close relationship between HCW and SBW. Similarly, correlations of CLMA and CFAT with RP weights and percentages were very similar to those observed for live ultrasound measurements which are according to the expected due to the high correlations between in vivo and carcass measurements.

Fat trimmings weight was positively correlated with all in vivo and carcass measurements. SBW and $\mathrm{HCW}$ were the variables with the strongest associations with fat trimming weight ( $\mathrm{r}=0.83$ and $\mathrm{r}=0.87$, respectively). These traits were only moderately related to fat trimming percentage $(\mathrm{r}=0.55$ and 0.59 , respectively); however, correlation coefficients were greater than those found for RP percentage, probably because of the higher fat deposition of heavier cattle.

Correlations of fat measurements (UFAT, URFAT, and CFAT) with both fat trimmings weight and percentage were very similar, ranging from 0.62 to 0.66 . Measurements of fat at the 12th rib level both in vivo and post-mortem showed slightly lower correlations with those traits $(\mathrm{r}=0.62)$ when compared with URFAT ( $\mathrm{r}=0.66$ and $\mathrm{r}=0.64$, respectively).

In general, URFAT showed higher correlations with all traits evaluated when compared with UFAT, except for pistola hindquarter RP percentage, in which the correlation was the same $(\mathrm{r}=-0.42)$. These results differ from those commonly found in the literature, in which fat measurements at the level of the 12th rib has been reported to be more correlated with retail product weights and percentages (Greiner et al., 2003; Tait et al., 2005) and with fat trimmings weight and percentage (Tait et al., 2005; Williams et al., 1997).

The higher correlation of URFAT with all traits observed in this study is probably due to differences in growth and distribution of fat in Nellore cattle compared with European breeds. The average of URFAT in this study was higher $(9.2 \mathrm{~mm})$ than the UFAT at the 12 th rib level $(6.4 \mathrm{~mm})$, although the coefficients of variation were quite similar, which is in agreement with previous studies in Nellore cattle (Gomes et al., 2009). In the studies of Greiner and Tait, cattle were produced by mating Hereford, Angus and MARCIII dams to sires from Hereford, Angus and other breeds. This type of cattle is usually fatter the zebu breeds in similar maturity degrees and present greater subcutaneous fat thicknesson the longissimus muscle. The UFAT ranged from 2.1 to 20.1 in the first and 2.8 to 21.1 in the last study mentioned, which is much greater than the variation found in the current study, which was 1.9 to $14.8 \mathrm{~mm}$. Therefore, differences in breeds and nutritional management may have led to distinct relationships of fat measurements with retail cut production across studies. This suggests that breed-specific equations are necessary to correctly predict retail cut production.

All carcass traits were included in models to predict weighs and percentages of RP and trim fat. Carcass traits accounted for $97 \%$ of the variation observed in RP weight and $94 \%$ in pistola hindquarter RP weight (Table 3). When retail cuts were expressed as percentage, the $\mathrm{R}^{2}$ values dropped to $36 \%$ for both traits.

Our results are in agreement with those found by Luchiari Filho (1986) in zebu cattle, in which carcass traits explained $97 \%$ of RP weight and 34\% of RP percentage. Williams et al. (1997) reported that carcass traits explained $83 \%$ of RP weight and $31 \%$ of RP percentage in Hereford and Angus cattle. These results are similar to the associations observed by Realini et al. (2001), who found that carcass traits explained $87 \%$ and $40 \%$ of RP weight and percentage, respectively, in Hereford cross steers. However, Greiner et al. (2003) reported higher $\mathrm{R}^{2}$ values ( $68 \%$ to $72 \%$ ) when predicting RP percentage, which could be explained by the large variation of genetic groups and carcass composition of animals used in their study.

Carcass traits explained $36 \%$ of the variation of pistola hindquarter RP percentage. Similar results were obtained

Table 3 - Regression equations for predicting retail product, pistola hindquarter and fat trimming weights and percentages from carcass measurements

\begin{tabular}{|c|c|c|c|c|c|c|c|c|}
\hline \multirow{2}{*}{ Dependent variable } & \multirow{2}{*}{ SEP } & \multirow{2}{*}{$\mathrm{R}^{2}$} & \multirow{2}{*}{$\mathrm{Cp}$} & \multicolumn{5}{|c|}{ Partial regression coefficients } \\
\hline & & & & Intercept & HCW & CLMA & CFAT & KPIF \\
\hline KGRP & 4.82 & 0.97 & 3.68 & -1.184 & $0.635^{* * *}$ & $0.270^{\text {**** }}$ & $-0.398^{* *}$ & - \\
\hline PRP & 1.28 & 0.36 & 5.00 & $70.524^{* * *}$ & $-0.014^{* * *}$ & $0.084^{* * *}$ & $-0.132^{* *}$ & $-0.374^{* *}$ \\
\hline KGRPPHQ & 3.09 & 0.94 & 5.00 & $6.960^{* *}$ & $0.278^{* * *}$ & $0.180^{* * * *}$ & $-0.194^{*}$ & $-0.987^{* *}$ \\
\hline PRPPHQ & 1.12 & 0.36 & 5.00 & $35.912^{* * *}$ & $-0.015^{* * *}$ & $0.057^{\text {**** }}$ & $-0.071^{*}$ & $-0.452^{\text {**** }}$ \\
\hline KGTFAT & 3.91 & 0.85 & 5.00 & $-19.333^{* * *}$ & $0.202^{* * *}$ & $-0.189^{* * *}$ & $0.700^{* * * *}$ & $1.203^{* *}$ \\
\hline PTFAT & 0.65 & 0.58 & 5.00 & $3.204^{* * * *}$ & $0.012^{* * *}$ & $-0.031^{* * *}$ & $0.116^{* * * *}$ & $0.196^{* *}$ \\
\hline
\end{tabular}

HCW - hot carcass weight; KPIF - kidney, pelvic and inguinal fat weight expressed as percentage of total carcass weight; CLMA - carcass longissimus muscle area between the 12th and 13th ribs; CFAT - carcass subcutaneous fat thickness between the 12th and 13th ribs; KGRP - weight of carcass retail product; PRP - retail product weight expressed as percentage of carcass weight; KGRPPHQ - weight of retail product in the pistola hindquarter ; PRPPHQ - retail product in the pistola hindquarter expressed as percentage of carcass weight; KGTFAT - weight of carcass trimmed fat ( $5 \mathrm{~mm})$; PTFAT - trimmed fat weight expressed as a percentage of carcass weight; SEP - standart error of prediction.

$* * * \mathrm{P}<0.0001 ; * * \mathrm{P}<0.001 ; * \mathrm{P}<0.05$. 
by Tait et al. (2005), who reported an $\mathrm{R}^{2}$ value of 0.30 in the four primals. Tarouco et al. (2007) reported that carcass traits (HCW, CLMA and carcass conformation) explained $67 \%$ of variation in pistola hindquarter RP when trimmings fat and bone percentages were included in the model.

Carcass measurements explained $85 \%$ and $58 \%$ of trimmings fat weight and percentage, respectively. These $\mathrm{R}^{2}$ values are very similar to those reported by Realini et al. (2001) (82\% and 50\%, respectively). However, the results found in this investigation are higher than values reported by Luchiari Filho (1986), using data from females, intact and castrated males of Zebu breeds (57\% and 36\%, respectively). The differences between studies could be related to factors such as sample size, breed influence and data variability, as well as differences in how traits were evaluated and how data were fitted in the regression models.

Among all in vivo traits evaluated, only SBW and ULMA had a significant effect on RP weight, explaining $93 \%$ of the variation of this trait (Table 4 ).

Differences in accuracy when predicting RP weight using in vivo or carcass measurements are partially explained by the different degree of associations of SBW and $\mathrm{HCW}$ with that trait, used in live or carcass models, respectively. Hot carcass weight explained 96\%, whereas SBW explained $89 \%$ of the variation in RP weight. This fact contributed to reduce the difference in the power of estimating RP weight from in vivo and carcass measurements to only $4 \%$, (93\% vs $97 \%$, respectively), which resulted in similar accuracy using either in vivo or carcass traits.

In vivo fat measurements (UFAT and URFAT) were not significant predictors of RP weight. Shrunk body weight and ULMA have been reported to be the most important live traits associated with RP weight, whilst fat measurements are more closely linked to percentage of retail products (Williams et al., 1997; Realini et al., 2001).
Despite their smaller contribution to predicting weight of cuts, fat measurements have been reported to be significant traits when animals show high degree of fatness (Realini et al., 2001), unlike the current study.

Many investigations have shown some variability in accuracy of equations to predict RP percentage from live animal measurements. Greiner et al. (2003) reported that measurements of live animals explained up to $67 \%$ of percentage and up to $83 \%$ of weight. Wolcott et al. (2001) found that pre-slaughter measurements of SBW, ULMA and URFAT explained $56 \%$ of RP percentage variation, while Herring et al. (1994) and Williams et al. (1997) described that live measurements explained up to $32 \%$.

In the present study, live animal traits explained 39\% of RP percentage and $33 \%$ of pistola hindquarter RP percentage, which differs from the findings of Greiner et al. (2003) and Wolcott et al. (2001), but is similar to results reported by Herring et al. (1994) and Williams et al. (1997). Despite the similarity or lack of similarity of determination coefficients of equations obtained in different studies, partial regression coefficients are very different across them, which can have a great impact on accuracy of prediction of retail cuts.

The current study showed that URFAT had a significant contribution for predicting carcass composition of Nellore steers. The relative importance of URFAT and UFAT in the prediction equations may be influenced by the relationship between these subcutaneous depots. Fat partitioning within the subcutaneous depot between rib and rump sites is affected by breed (Hopkins et al., 1993; Walmsley et al., 2010). Walmsley et al. (2010), who investigated the relationship between rump and rib fat in Bos taurus and Bos indicus, found that the former had greater fat depth at the rump at any given rib fat depth, compared with Bos taurus cattle.

The pistola hindquarter (\#1020, UNECE, 2006) is an economically important trait for the beef industry because it comprises the more valuable cuts of meat in the carcasses.

Table 4 - Regression equations for prediction of retail product, pistola hindquarter and fat trimming weights and percentages from live measurements

\begin{tabular}{|c|c|c|c|c|c|c|c|c|}
\hline \multirow{2}{*}{ Dependent variable } & \multirow{2}{*}{ SEP } & \multirow{2}{*}{$\mathrm{R}^{2}$} & \multirow{2}{*}{$\mathrm{Cp}$} & \multicolumn{5}{|c|}{ Partial regression coefficients } \\
\hline & & & & Intercept & SBW & ULMA & UFAT & URPFAT \\
\hline KGRP & 6.81 & 0.93 & 1.2 & $-37.253^{* * *}$ & $0.367^{* * *}$ & $0.746^{* * *}$ & - & - \\
\hline PRP & 1.25 & 0.39 & 5.0 & $69.901^{* * *}$ & $-0.006^{* *}$ & $0.073^{* * *}$ & $-0.098^{*}$ & $-0.186^{* * *}$ \\
\hline PRPPHQ & 1.15 & 0.33 & 3.5 & $35.825^{* * * *}$ & $-0.012^{* * *}$ & $0.060^{* * *}$ & - & $-0.104^{* * * *}$ \\
\hline KGTFAT & 4.63 & 0.79 & 3.2 & $25.243^{* * *}$ & $0.100^{* * *}$ & - & $0.674^{* *}$ & $0.769^{* * *}$ \\
\hline PTFAT & 0.67 & 0.55 & 5.0 & $3.433^{* * *}$ & $0.005^{* * *}$ & $-0.020^{* *}$ & $0.108^{* * *}$ & $0.101^{* * *}$ \\
\hline
\end{tabular}

SBW - shrunk body weight on scan date; ULMA - ultrasound of the longissimus muscle area between the 12th and 13th ribs; UFAT - ultrasound of subcutaneous fat thickness between the 12th and 13th ribs; URFAT - ultrasound subcutaneous fat measured over the biceps femoris muscle; KGRP - weight of carcass retail product; PRP - retail product weight expressed as percentage of carcass weight; KGRPPHQ - weight of retail product in pistola hindquarter; PRPPHQ - retail product in the pistola hindquarter expressed as percentage of carcass weight; KGTFAT - weight of carcass trimmed fat (5 mm); PTFAT - trimmed fat weight expressed as a percentage of carcass weight; SEP - standart error of prediction. $* * * \mathrm{P}<0.0001 ; * * \mathrm{P}<0.001 ; * \mathrm{P}<0.05$ 
Therefore, accurate estimation of retail product in whole carcass or pistola hindquarter could help producers and the industry to drive their production systems to a more efficient use of this information.

In vivo measurements of SBW and ULMA were the variables significantly associated with pistola hindquarter RP weight (Table 4), as found for RP weight despite the smaller accuracy $\left(R^{2}=0.93\right.$ and 0.87 for $R P$ weight and pistola hindquarter RP weight, respectively).

The full model to predict pistola hindquarter RP weight using carcass traits explained $94 \%$ of variation of this trait while in vivo measurements explained $87 \%$. Similar pattern, but with a smaller difference was observed for pistola hindquarter RP percentage using carcass $\left(\mathrm{R}^{2}=0.36\right)$ or in vivo $\left(\mathrm{R}^{2}=0.33\right)$ measurements.

There are few studies in the literature on the association between live measurements and retail cuts in the pistola hindquarter. According to Tait et al. (2005) live measurements explained from $45 \%$ to $49 \%$ of the variation of retail cuts in the four primal, while Tarouco et al. (2007) observed that the in vivo measurements only explained $16 \%$ to $18 \%$ of the pistola hindquarter RP percentage variation in Braford young bulls. In the current study, intermediary accuracies to these studies were observed for the prediction of that trait using in vivo measurements.

Unlike the observed for RP percentage, UFAT was not a significant trait in the prediction of pistola hindquarter RP percentage, whereas URFAT, ULMA and SBW were highly significant $(\mathrm{P}<0.0001)$. These results also differ from those reported by Tait et al. (2005), in which UFAT was a highly significant variable to predict retail cuts in the four primal, and URFAT did not enter the model.

Although the live measurements showed a smaller coefficient of determination at the determination of pistola hindquarter RP percentage $\left(\mathrm{R}^{2}=0.33\right)$ when compared with $R P$ percentage $\left(R^{2}=0.39\right)$, the accuracy was very similar to that obtained using carcass traits $\left(\mathrm{R}^{2}=0.36\right)$, indicating that live measurements can be used to estimate retail cuts in that primal.

Fat trimmings are a relevant trait to be predicted accurately, once its reduction may be a complementary selection priority which could help to increase efficiency and reduce waste associated with meat production (Lambe et al., 2010). In this study, in vivo measurements explained $79 \%$ and $55 \%$ of variation in fat trimmings weight and percentage, respectively (Table 4), whereas carcass measurements explained $85 \%$ and $58 \%$, respectively (Table 3 ).

These values indicate better accuracies than those reported by Realini et al. (2001), in which live measurements
(SBW, ULMA, UFAT and URFAT) explained 69\% of trimmings weight and $43 \%$ of trimmings percentage. Williams et al. (1997) also reported smaller coefficients of determination for those traits ( 0.58 and 0.30 , respectively). Nevertheless, Realini et al. (2001) found a less clear effect of URFAT at the prediction of RP and trimmable fat weights and percentages.

As expected, fat measurements (UFAT and URFAT) were positively associated to fat trimmings. Ultrasound rump fat alone explained $71 \%$ of variation in trimmings percentage, while UFAT contributed to an additional $4 \%$. Body weight contributed positively to an increase both trimming weight and percentage, while ULMA was negatively associated with trimming percentage.

Although the equations for prediction of retail cuts herein presented showed accuracies within the range found in the literature, they markedly differ in relation to the magnitude of some parameters, as a consequence of breed differences in tissue deposition and distribution. Therefore, although equations reported in this study have not been validated yet, they are likely to improve the accuracy of prediction of retail cut yields in Nellore cattle, since they were developed using this specific genetic group. Furthermore, the present study also contributes to the characterization of carcass quality and composition of Nellore breed, for which information is very limited, despite their widespread use in the Brazilian herd.

\section{Conclusions}

The results from this research indicate that weight and percentage of retail products and trimmable fat can be estimated from live animal measurements with similar accuracy and predictive power to equations developed from carcass measurements. Further studies with animals of different sexes and zebu breed groups are necessary to validate these models.

\section{Acknowledgments}

The authors thank the Foundation for Research Support of Sao Paulo State (Fundação de Amparo à Pesquisa do Estado de São Paulo, FAPESP), SP, Brazil, for supporting this study (Proc. 04/14880-3).

\section{References}

BALL, B.; JOHNSON, E.R. The influence of breed and sex on saleable beef yield. Australian Journal of Experimental Agriculture, v.29, p.483-487, 1989. 
GOMES, R.C.; LEME, P.R.; SILVA, S.L. et al. Carcass quality of feedlot finished steers fed yeast, monensin and the association of both additives. Arquivo Brasileiro de Medicina Veterinária e Zootecnia, v.61, n.3, p.648-654, 2009.

GREINER, S. P.; ROUSE, G. H.; WILSON, D. E. et al. Accuracy of predicting weight and percentage of beef carcass retail product using ultrasound and live animal measurements. Journal of Animal Science, v.81, p.466-473, 2003.

HEDRICK, H.B. Methods of estimating live animal and carcass composition. Journal of Animal Science, v.57, p.1316-1327, 1983.

HERRING, W.O.; WILLIAMS, S.E.; BERTRAND, J.K. et al. Comparison of live and carcass equations predicting percentage of cutability, retail product weight, and trimmable fat in beef cattle. Journal of Animal Science, v.72, p.1107-1118, 1994.

HOPKINS, D.L.; BROOKS, A.A.; JOHNSTON, A.R. Factors affecting subcutaneous fat depth at two sites on beef carcasses. Australian Journal of Experimental Agriculture, v.33, p.129-133, 1993.

LAMBE, N.R.; ROSS, D.W.; NAVAJAS, E.A. et al. The prediction of carcass composition and tissue distribution in beef cattle using ultrasound scanning at the start and/or end of the finishing period. Livestock Science, v.131, p.193-202, 2010.

LUCHIARI FILHO, A. Characterization and prediction of carcass cutability traits of zebu and crossbreed types of cattle produced in southeast Brazil. 1986. 89f. Thesis (Doctor of Philosophy) Kansas State University, Manhattan.

MALLOWS, C.L. Some comments on CP. Technometrics, v.15, p.661-675, 1973.

MILLEN, D.D.; PACHECO, R.D.L.; ARRIGONI, M.D.B. et al. A snapshot of management practices and nutritional recommendations used by feedlot nutritionists in Brazil. Journal of Animal Science, v.87, p.3427-3439, 2009.

REALINI, C.E.; WILLIAMS, R.E.; PRINGLE, T.D. et al. Gluteus medius and rump fat depths as additional live animal ultrasound measurements for predicting retail product and trimmable fat in beef carcasses. Journal of Animal Science, v.79, p.1378-1385, 2001.

TAIT, R.G.; WILSON, D.E.; ROUSE, G.H. Prediction of retail product and trimmable fat yields from the four primal cuts in beef cattle using ultrasound or carcass data. Journal of Animal Science, v.83, p.1353-1360, 2005

TAROUCO, J.U.; LOBATO, J.F.P.; TAROUCO, A.K. et al. Comparação entre medidas ultra-sônicas e da carcaça na predição da composição corporal em bovinos. Estimativas do peso e da percentagem dos cortes comerciais do traseiro. Revista Brasileira de Zootecnia, v.36, p.2092-2101, 2007.

UNITED NATIONS ECONOMIC COMMISSION FOR EUROPE UNECE. 2006. Bovine meat carcasses and cuts. Available at: $<$ http://www.unece.org/trade/agr/meetings/wp.07/2006/2006_11e. pdf> Accessed on: June 5, 2007.

WALMSLEY, B.J.; WOLCOTT, M.L.; McPHEE, M.J. Modeling the relationship between scanned rump and 12th-rib fat in young temperate and tropical bovines: Model development and evaluation. Journal of Animal Science, v.88, p.1848-1859, 2010.

WILLIAMS, R.E.; BERTRAND, J.K.; WILLIAMS, S.E. Biceps femoris and rump fat as additional ultrasound measurements for predicting retail product and trimmable fat in beef carcass. Journal of Animal Science, v.75, p.7-13, 1997.

WOLCOTT, M.L.; THOMPSON, J.M.; PERRY, D. The prediction of retail beef yield from real time ultrasound measurements on live animals at three stages through growout and finishing. Australian Journal of Experimental Agriculture, v.41, p.1005-1011, 2001. 